\title{
Resource Factors Affecting Labour Demand for Textile and Garment Industry in Thailand
}

\author{
K. Leerojanaprapa ${ }^{1, *}$ and K. Bhundarak ${ }^{2}$ \\ ${ }^{1}$ Department of Statistics, Faculty of Science, King Mongkut's Institute \\ of Technology Ladkrabang, Ladkrabang, Bangkok, 10520, Thailand \\ ${ }^{2}$ Thammasat Business School, Thammasat University, Phranakorn, \\ Bangkok, 10200, Thailand \\ E-mail:kanogkan.le@kmitl.ac.th;komn@tbs.tu.ac.th \\ *Corresponding Author
}

Received 17 August 2017; Accepted 21 October 2017;

Publication 25 November 2017

\begin{abstract}
This article aims to define the correlation between particular resource variables with the labour demand and propose forecasting model for labor demand in textile industry represented by fiber manufacturing companies (ISIC CODE 13111) and in garment industry represented by the manufacturer of work wear (ISIC CODE 14111) in Thailand by multiple regression with and without variable transformation. This research defined eight independent variables: Land capital $\left(\mathrm{X}_{1}\right)$, Buildings capital $\left(\mathrm{X}_{2}\right)$, Machinery capital $\left(\mathrm{X}_{3}\right)$, Working capital $\left(\mathrm{X}_{4}\right)$, Factory area $\left(\mathrm{X}_{5}\right)$, Building area $\left(\mathrm{X}_{6}\right)$, Horsepower $\left(\mathrm{X}_{7}\right)$, and Type of manufacturer $\left(\mathrm{X}_{8}\right)$. Secondary data were acquired from the Department of Industrial Works where registered companies submitted their essential data and obtained the approval permit in doing business during 2015. The result of analysis by multiple linear regression are used to explain how particular resource factors affect labour demand for textile and garment industry in Thailand by comparing between textile and garment industry. The results from the study also reveal that transforming labor demand (Y) and Horsepower $\left(\mathrm{X}_{7}\right)$ with logarithm satisfy all regression assumptions and the forecasting models are also proposed.
\end{abstract}

Journal of Industrial Engineering and Management Science, Vol. 1, 263-288. doi: 10.13052/jiems2446-1822.2017.013

This is an Open Access publication. (c) 2017 the Author(s). All rights reserved. 


\section{K. Leerojanaprapa and K. Bhundarak}

Keywords: Multiple regression analysis, workforce, textile and garment manufacturers.

\section{Introduction}

The formal definition of labor that is "The labor force is the number of people aged 16 and older who are either working or actively looking for work. It does not include active-duty military personnel or institutionalized population, such as prison inmates" [1]. Generally, labor is the indicator of the economic growth in a particular country and it is one of main decision factors for manufacturer relocation of a global companies.

In manufacturer's point of view on production activities, labor is one of the three classic economic resources of production including land, labor, and capital [2]. Apart from those three factors which are called as Primary factors, materials and energy are considered as secondary factors in classical economics since they become a part of the product or are significantly transformed by the production process. Particular companies or manufacturers need to predict workload and the required staff for production without interruptions. However, levels of labor demands for individual industries vary. Furthermore, labor becomes more crucial especially for labor intensive industries such as textile and garment industry.

Textile and garment industries were established in Thailand for a long time and they are one of the primary industries in Thailand. The textile and garment industry significantly contributes to Thailand's economic and social development. In 2015 (January-October) total textile export value was forecasted at $\$ 5,359.1$ million USD and garment export value of $\$ 2,407.92$ million USD [3]. At present, textile and garment industries in Thailand are challenged by labor shortages to support the industry. As a result of the 'Nationwide Minimum Wage Policy' that employers in Thailand must pay a minimum wage of 300 Baht (around \$10) per day for all provincial areas, workers prefer working in their hometown rather than moving to the big cities as they can earn the same wage. Furthermore, some workers prefer working in other industries e.g. electronics or computer industry, automotive industry which they may expect a better working environment. Thai textile and garment manufacturers should be able to have a good plan to prepare enough workers for their production by forecasting demanded workers in order to support production in time. The entrepreneurs in textile and garment should be able to prepare the sufficient labors by predicting their labor demand from the capacity and resources of their production to prevent them from labor shortages. 
The aim of this study is to model the relationship between labor demand and a set of resource factors $\left(\mathrm{X}_{\mathrm{j}}\right)$ for textile and garment manufacturing companies.

The structure of this article is as follows: theories and methods for this research are set in the next section. The literature review about perceptions in labor demand in different industries and method are also identified. Subsequently, the data and associated variables are defined and shown in conceptual framework. Next results of analysis that serve the objectives of this research are presented. Conclusion and further studies are drawn in the last section.

\section{Theories and Methods}

Multiple linear regression model is the main analysis for this research. Relevant theories and methods are explained in this section.

\subsection{Multiple Regression Model}

Generally, multiple linear regression model defines the relationship between a dependent variable (Y) and independent variable(s) (Xs). The general form of linear relationship is defined by Equation (1) when $\varepsilon_{\mathrm{i}}$ is an unobserved random variable that adds noise to the linear relationship. These $\mathrm{n}$ equations $(\mathrm{i}=1,2,3, \ldots, \mathrm{n})$ are stacked together and written in vector form as Equation (2).

$$
\begin{aligned}
\mathrm{Y}_{\mathrm{i}} & =\beta_{0}+\beta_{1} \mathrm{X}_{1 \mathrm{i}}+\beta_{2} \mathrm{X}_{2 \mathrm{i}}+\cdots+\beta_{\mathrm{k}} \mathrm{X}_{\mathrm{ki}}+\varepsilon_{\mathrm{i}} \\
\mathbf{Y} & =\mathbf{X} \boldsymbol{\beta}+\boldsymbol{\varepsilon}
\end{aligned}
$$

Since $\beta$ is the parameter vector and unknown, the Ordinary Least Square (OLS) method minimizes the sum of squared residuals, and leads to a closed-form expression for the estimated value of the unknown parameter $\beta: \hat{\beta}$.

$$
\hat{\boldsymbol{\beta}}=\left(\mathbf{X}^{\mathrm{T}} \mathbf{X}\right)^{-1} \mathbf{X}^{\mathrm{T}} \mathbf{y}
$$

The regression analysis implementing stepwise approach was performed by using Statistical Package for the Social Science (SPSS) for windows version 19.0.

\subsection{Modeling Approaches}

Three main approaches can be used to reduce independent variables for a multiple linear regression. Forward approach can choose each variable in 
the equation with the smallest probability of $\mathrm{F}$ until as long as the value is smaller than defined probability to enter. On the other hand, backward approach can first enter all variables into the equation and then sequentially remove them. At each step, the largest probability of $F$ is removed (if the value is larger than probability to remove. Alternatively, stepwise mixes between both approaches since selected variables are input that increase probability of F by setting probability to enter (at least 0.05 ) and exclude them if the increase probability of $\mathrm{F}$ is less than the setting probability (greater than 0.1 ). For this study, stepwise is the main selected approach for regression analysis.

\subsection{Model Assumptions}

\subsubsection{Multivariate normality}

Regression model is developed under Normality assumption which identified that all variables have Normal distribution. Testing of this assumption can be implemented by several methods such as visual inspection of data plots or P-P plots that plot the cumulative probability of a variable against the cumulative probability of a particular distribution (e.g. normal distribution). This is the expected value that the score should have in a normal distribution. The scores are then converted to z-scores. The actual z-scores are plotted against the expected z-scores. If the data are normally distributed, the result would be a straight diagonal line.

Generally, data cleaning can also be important since outliers which can be one of the causes of Non-normally distribution removal of univariate and bivariate outliers can reduce the probability of Type I and Type II errors, and improve accuracy of estimates [4]. In another way, case transformations (e.g., square root, log, or inverse) can also improve normality.

Furthermore, outlier is one of the main causes of non-normality, so during data preparation, outliers or unusual of all cases can be defined by considering Cook's distance. A large Cook's D indicates that excluding a case from computation of the regression statistics can change the coefficients of the regression model.

$$
D_{i}=\frac{e_{i}^{2}}{s^{2} p}\left[\frac{h_{i}}{\left(1-h_{i}\right)^{2}}\right]
$$

When

$$
\begin{aligned}
& s^{2}=(n-p)^{-1} \mathbf{e}^{T} \mathbf{e} \\
& h_{i}=\mathbf{x}_{i}^{T}\left(\mathbf{X}^{T} \mathbf{X}\right)^{-1} \mathbf{x}_{i} \\
& p \text { is number of independent variables }
\end{aligned}
$$




\subsubsection{Assumption of a linear relationship}

The regular multiple regression model as shown in Equation (1) represents linear relationship between a dependent variable and a set of independent variables. In order to examine this assumption, residual plots depict the plots of the standardized residuals as a function of standardized predicted values. The scatter plot of residuals indicates linear relationships when they randomly spread around 0 without curvilinear pattern.

\subsubsection{Assumption of homoscedasticity}

Homoscedasticity means the variance of errors across all levels of the independent variables are constant. Accordingly, this assumption can be checked by visual examination of a residual plot (as defined in the Assumption of a linear relationship). When residuals are randomly spread around 0 (the horizontal line) with the same variance (same density both above and below the line), homoscedasticity is assumed.

\subsubsection{No autocorrelation}

When residuals are not independent from each other, autocorrelation can occur. Autocorrelation can be checked by using scatter plot between residuals and sequence of data. The autocorrelation occurs when the value of $y_{(t+1)}$ is dependent from the value of $y_{(t)}$. Durbin-Watson's test is employed to show whether the residuals are linearly auto-correlated or not. The value of $1.5<$ Durbin-Watson $<2.5$ shows that there is no autocorrelation in the multiple linear regression data.

Dubin-Watson test statistic is expressed as:

$$
d=\frac{\sum_{t=2}^{T}\left(e_{t}-e_{t-1}\right)^{2}}{\sum_{t=1}^{T} e_{t}^{2}}
$$

When

$T$ is number of observations

\subsubsection{Multicollinearity}

Multicollinearity is defined as the influence of one independent variable on all other independent variables. The relationship among independent variables is not allowed for multiple regression analysis. If the Tolerance of independent 
variable is less than 0.2 or Variance Inflation Factor (VIF) value is greater than 10 , the model indicates the presence of multicollinearity.

$$
V I F_{i}=\frac{1}{1-R_{i}^{2}}
$$

When

$R_{i}^{2}$ is a multiple correlation coefficient for predict $x_{i}$ from other independent variables.

There is no formal VIF value for determining presence of multicollinearity. Values of VIF that exceed 10 are often regarded as indicating multicollinearity, but in weaker models values above 2.5 may be a cause of concern.

\subsection{Variable Transformation}

Variable transformation can be applied to transform dependent and/or independent variables to achieve linearity for regression assumption (2.3.2). Some common methods are available in literature as shown in Equations (7)-(11).

$$
\begin{aligned}
& \text { Exponential model } \log \left(y_{i}\right)=b_{0}+b_{1} x_{i} \\
& \text { Quadratic model } \operatorname{sqrt}\left(y_{i}\right)=b_{0}+b_{1} x_{i} \\
& \text { Reciprocal model } \quad 1 / y_{i}=b_{0}+b_{1} x_{i} \\
& \text { Logarithmic model } y_{i}=b_{0}+b_{1} \log \left(x_{i}\right) \\
& \text { Power model } \log \left(y_{i}\right)=b_{0}+b_{1} \log \left(x_{i}\right)
\end{aligned}
$$

In practice, these methods need to be tested on the data to which they are applied to be ensured that they increase rather than decrease the linearity of the relationship. Testing the effect of a transformation method investigates the residual plots and value of correlation coefficients. When the residual plot from the transformation regression equation is better spread around 0 and has higher value of correlation coefficients than the initial linear regression.

The model becomes very complex if multiple independent variables are transformed with different functions and the action make the transformation equation too complex to understand. As a result, this paper focuses on two ways of transforming. One is to model the relation of the transforming independent variable with defined multiple dependent variables and another is to model with only one transforming independent variable. This article will show the results of comparison of those transformed model with the initial linear regression. 


\section{Literature Review}

Literature in work assessment of textile and garment industry mainly focuses on two areas: quality (skill needs) and quantity (amount of workers). This study will focus only on the quantity scope. The manpower projection on the future of particular countries by age are the conventional information in macroeconomics level to analyse manpower supply such as report on man power projection for Hong Kong [5]. In textile and garment, Nadvi et al. [6] studied the employment and showed the output per worker in Vietnam by historical data.

In the company level, workforce management is one of the keys to success in business. However, the supply of workers in textile and garment became lower than demand. High turnover rate becomes a crucial problem for the UK clothing manufacturers and there are differences in particular categories of clothing product [7]. Forecasting worker demand for individual companies is a necessity and different methods to support workforce planning. Dong et al. [8] developed supporting software called iRDM to minimize the total cost by considering particular positions. Alternatively, by focusing to estimate demand of workers in a company from variables related to the business growth, regression method was employed. For instance, Scheffler et al. [9] developed regression model by using World Bank and WHO data from 1980 to 2010 for 158 countries and found that there were shortages of physicians for many countries in the WHO African Region in 2015.

In addition, construction industry also faces with the lack of labor similar to textile and garment industry. Therefore, workforce planning is presented in the literature. Liu et al. [10] implemented a vector error correction (VEC) model to show that there proposed model can model the construction workforce demand and also examine the impact of global economic climate to the labor market. Their model applied with the time series and showed the application in the empirical estimation in Australia's constructions workforce demand to show adequately stable, robust and efficient to forecast the short- to mediumterm aggregate workforce demand. In addition, Wong, Chan and Chiang [11] also proposed a vector error correction (VEC) model to forecast construction manpower demand and compare the model accuracy with the Box-Jenkins approach [12] and the multiple regression analysis. They defined the factors causing manpower demand in the construction industry as construction output, labor productivity, real wage, material price, and interest rate. They showed the application from survey data of construction employment obtained from household surveys in Hong Kong. 


\section{Data and Variables}

\subsection{Data}

Secondary data were acquired from the Department of Industrial Works where all companies in Thailand registered and obtained their approval permit for doing business in 2015. The cross-sectional data of the textile industry is represented by manufacturers of the preparation of textile fibers (ISIC CODE 13111), and data of the garment industry is represented by the manufacturers of work wear (ISIC CODE 14111). The data acquired from these two sectors are employed for this research.

\subsection{Variable in Regression Model}

Dependent variable and independent variables are identified as below and they are shown by conceptual framework for this study as Figure 1.

\subsubsection{Dependent variable}

Labor demand represents the required number of workers including skilled and non-skilled workers, which is identified as dependent variables in this research.

\subsubsection{Model and variables}

Four dimensions of manufacturing capacity are able to predict the total number of workers: Capital asset which can represent the growth of business (Land capital, Buildings capital, Machinery capital and Working capital),

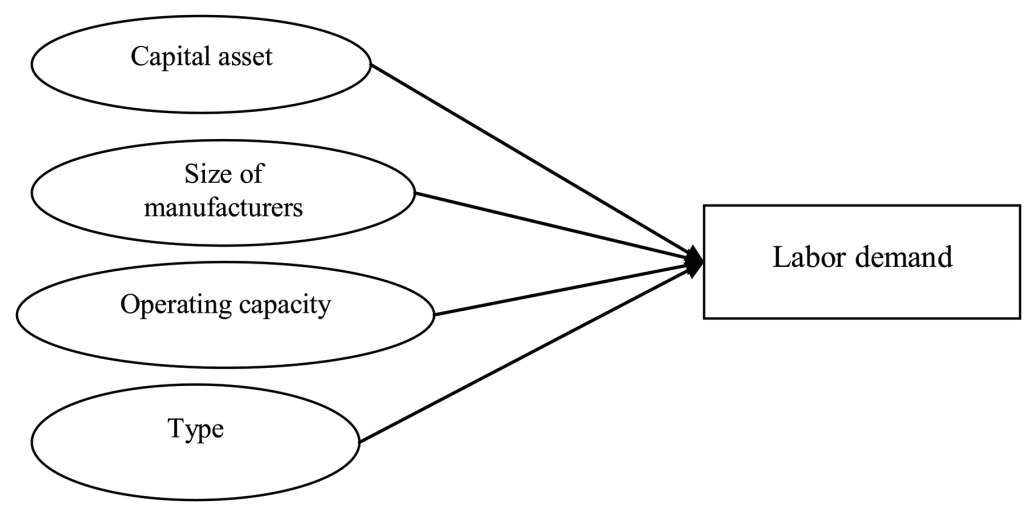

Figure 1 Conceptual framework. 
Size of manufacturers (Factory area and Building area) and Operating capacity (Horsepower). Number of workers engaged in manufacturing and primary horsepower are related [13]. The last factor is determined by given Type of manufacturers. According to the defined category of manufacturing companies, two groups of the industry are as defined.

The manufacturer of the preparation of textile fibers (ISIC CODE 13111):

1. Up to 50 horsepower, which no bleaching, dyeing process,

2. Greater than $50 \mathrm{hp}$ machines or plants of any size, with bleaching, dyeing process.

The manufacturer of work wears (ISIC CODE 14111):

1. Up to 50 workers,

2. Greater than 50 workers.

The group of manufacturers is identified as a Dummy variable in regression model.

$$
\hat{\mathrm{Y}}=\hat{\beta}_{0}+\hat{\beta}_{1} \mathrm{X}_{1}+\hat{\beta}_{2} \mathrm{X}_{2}+\cdots+\hat{\beta}_{8} \mathrm{X}_{8}
$$

Where

$$
\begin{aligned}
\hat{\mathrm{Y}} & =\text { Labor demand of a manufacturer (persons) } \\
\mathrm{X}_{1} & =\text { Land capital }(1,000 \text { Baht }) \\
\mathrm{X}_{2} & =\text { Buildings capital }(1,000 \text { Baht }) \\
\mathrm{X}_{3} & =\text { Machinery capital }(1,000 \text { Baht }) \\
\mathrm{X}_{4} & =\text { Working capital }(1,000 \text { Baht }) \\
\mathrm{X}_{5} & =\text { Factory area }\left(\mathrm{m}^{2}\right) \\
\mathrm{X}_{6} & =\text { Building area }\left(\mathrm{m}^{2}\right) \\
\mathrm{X}_{7} & =\text { Horsepower }(\mathrm{hp}) \\
\mathrm{X}_{8} & =\text { Type of manufacturer }(\text { type } 1=1, \text { type } 2=0)
\end{aligned}
$$

\section{Results}

The results of regression model explain the relationship between labor demand and other 8 independent variables by industries. A multiple linear regression from raw data is the initial analysis and then all assumptions are investigated. If the model is not satisfied by all assumptions, variable transformation techniques are employed to determine which models are suitable with the 


\section{K. Leerojanaprapa and K. Bhundarak}

nature of the original data. The only way to determine which method is best is to try each and compare the result.

\subsection{Textile Manufacturers}

The manufacturers of the preparation of textile fibers are the representative of the textile industry for this study. There are 736 fiber manufacturing companies registered. The average number of workers in a particular manufacturer is 97.57 persons. The main asset for this industry is Machinery asset, as the mean of capital is greatest among the other three capital variables, at $37,224,690$ Baht. Mean of factory area is $16,588.00 \mathrm{~m}^{2}$ and mean of building area is $4,770.42 \mathrm{~m}^{2}$ (Table 1). Finally, the average operating capacity is $1,823.593 \mathrm{hp}$.

Linear regression is the most basic type of regression and commonly used predictive analysis as the linear equation between dependent variable (Y) and one or more independent variables (Xs). According to the record, there are 736 registered companies while completed data for all defined variables from 494 companies are available for analysis. The initial linear regression for Textile industries is constructed. Table 2 shows $F$ test in ANOVA analysis and explains that at least one of the defined independent variables is linearly related to the response variable since $p$-values is 0.000 which is less than the common alpha level of 0.01 . Therefore, the null hypothesis that all of the model coefficients are 0 is rejected.

According to the results in Table 3, the result of multiple linear regression shows influential variables of the labor demand that are Horsepower $\left(\mathrm{X}_{7}\right)$, Factory area $\left(\mathrm{X}_{5}\right)$, Building area $\left(\mathrm{X}_{6}\right)$, Working capital $\left(\mathrm{X}_{4}\right)$, and Machinery

Table 1 Characteristics of the Textile Manufacturers

\begin{tabular}{lcccc}
\hline Variable & Mean & SE & Min & Max \\
\hline Labor demand $(\mathrm{Y})$ & 97.57 & 7.7515 & 5 & $1,422.00$ \\
Land capital $\left(\mathrm{X}_{1}\right)$ & $5,863.39$ & 882.61 & 0 & $340,000.00$ \\
Building capital $\left(\mathrm{X}_{2}\right)$ & $9,712.28$ & $1,476.17$ & 0 & $343,925.00$ \\
Machinery capital $\left(\mathrm{X}_{3}\right)$ & $37,224.69$ & $7,662.75$ & 0 & $2,660,000.00$ \\
Working capital $\left(\mathrm{X}_{4}\right)$ & $15,849.44$ & $5,221.21$ & 0 & $2,360,000.00$ \\
Factory area $\left(\mathrm{X}_{5}\right)$ & $16,588.00$ & $1,959.84$ & 0 & $595,200.00$ \\
Building area $\left(\mathrm{X}_{6}\right)$ & $4,770.42$ & 483.86 & 0 & $156,950.00$ \\
Horsepower $\left(\mathrm{X}_{7}\right)$ & $1,823.593$ & 221.29 & 0 & $45,423.29$ \\
\hline
\end{tabular}


Table 2 Anova of the Linear Model (Textile industry)

\begin{tabular}{lccccc}
\hline Source & SS & df & MS & F & $p$-value \\
\hline Reg. & $7,243,745.37$ & 5 & $1,448,749.07$ & 166.82 & $0.000^{*}$ \\
Res. & $4,238,088.32$ & 488 & $8,684.61$ & - & - \\
Total & $11,481,833.69$ & 493 & - & - & - \\
\hline
\end{tabular}

*Significant at $p$-value $<0.01$ level.

Table 3 Coefficients of the Linear Model (Textile industry)

\begin{tabular}{lcccccc}
\hline Variable & $\hat{\beta}$ & $\mathrm{SE}$ & $\mathrm{t}$ & $p$-value & Tolerance & VIF \\
\hline Constant $)$ & 28.6246 & 4.6025 & 6.219 & $0.000^{*}$ & - & - \\
Horsepower $\left(\mathrm{X}_{7}\right)$ & 0.0180 & 0.0013 & 13.509 & $0.000^{*}$ & 0.4789 & 2.0880 \\
Factory area $\left(\mathrm{X}_{5}\right)$ & -0.0004 & 0.0000 & -16.711 & $0.000 *$ & 0.4519 & 2.2126 \\
Building area $\left(\mathrm{X}_{6}\right)$ & 0.0081 & 0.0005 & 15.286 & $0.000^{*}$ & 0.4058 & 2.4643 \\
Working capital $\left(\mathrm{X}_{4}\right)$ & 0.0004 & 0.0001 & 4.638 & $0.000^{*}$ & 0.3104 & 3.2214 \\
Machinery capital $\left(\mathrm{X}_{3}\right)$ & -0.0002 & 0.0001 & -2.795 & $0.005^{*}$ & 0.2471 & 4.0461 \\
\hline
\end{tabular}

$*$ Significant at $p$-value $<0.01$ level.

capital $\left(\mathrm{X}_{3}\right)$. Since coefficient $p$-value for all variables $<0.01$, regression equation to predict labor demand for a textile manufacturer is:

$\mathrm{Y}=28.6246+0.0180 \mathrm{X}_{7}-0.0004 \mathrm{X}_{5}+0.0081 \mathrm{X}_{6}+0.0004 \mathrm{X}_{4}-0.0002 \mathrm{X}_{3}$

The assumptions of regression analysis are investigated as follows. Firstly, testing multivariate normality by P-P plot (Figure 4(a)) shows that data scatter out from a straight diagonal line so multivariate normality is not assumed. Secondly, by considering the Figure 5(a); scatter plot of residuals indicates linear relationships when they randomly spread around 0 without curvilinear pattern but without the same variance (same density both above and below the zero line). Therefore, assumption of a linear relationship is assumed but homoscedasticity is not be assumed. Thirdly, the Durbin-Watson $=1.9654$, which is between the two critical values of 1.5 and 2.5. Therefore, we assume that there is no first order linear auto-correlation in the multiple linear regression data. Lastly, multicollinearity is considered in Table 3. There is no VIF for individual variables which is greater than 10 or Tolerance less than 0.2 but VIF values of Working capital $\left(\mathrm{X}_{4}\right)$ and Machinery capital $\left(\mathrm{X}_{3}\right)$ are greater than 2.5. Therefore, partial correlation between two independent variables are investigated as shown in Table 4 and found that the coefficient correlation of those two variables is -0.742 which is high and can be a cause of 
Table 4 Coefficient Correlations of Independent Variable

\begin{tabular}{lcccccccc}
\hline & $\left(\mathrm{X}_{1}\right)$ & $\left(\mathrm{X}_{2}\right)$ & $\left(\mathrm{X}_{3}\right)$ & $\left(\mathrm{X}_{4}\right)$ & $\left(\mathrm{X}_{5}\right)$ & $\left(\mathrm{X}_{6}\right)$ & $\left(\mathrm{X}_{7}\right)$ & $\left(\mathrm{X}_{8}\right)$ \\
\hline Land capital $\left(\mathrm{X}_{1}\right)$ & 1.000 & -0.248 & -0.027 & 0.077 & -0.107 & 0.080 & 0.002 & 0.043 \\
Building capital $\left(\mathrm{X}_{2}\right)$ & -0.248 & 1.000 & -0.157 & -0.243 & 0.153 & -0.184 & 0.037 & 0.038 \\
Machinery capital $\left(\mathrm{X}_{3}\right)$ & -0.027 & -0.157 & 1.000 & -0.742 & 0.252 & -0.219 & -0.138 & -0.006 \\
Working capital $\left(\mathrm{X}_{4}\right)$ & 0.077 & -0.243 & -0.742 & 1.000 & -0.100 & 0.080 & 0.104 & -0.017 \\
Factory area $\left(\mathrm{X}_{5}\right)$ & -0.107 & 0.153 & 0.252 & -0.100 & 1.000 & -0.834 & 0.270 & -0.063 \\
Building area $\left(\mathrm{X}_{6}\right)$ & 0.080 & -0.184 & -0.219 & 0.080 & -0.834 & 1.000 & -0.562 & 0.059 \\
Horsepower $\left(\mathrm{X}_{7}\right)$ & 0.002 & 0.037 & -0.138 & 0.104 & 0.270 & -0.562 & 1.000 & 0.038 \\
Type $\left(\mathrm{X}_{8}\right)$ & 0.043 & 0.038 & -0.006 & -0.017 & -0.063 & 0.059 & 0.038 & 1.000 \\
\hline
\end{tabular}

multivariate. Not all assumptions are satisfied so the linear regression model from the raw data should be improved by considering the suggestions given in Sections 2.3-2.4.

Firstly, we check whether the Worker demand (Y) that is marginally normally distributed. The histogram as show in Figure 2(a) shows that the Worker demand $(\mathrm{Y})$ is non-normal distribution with a right skew. Therefore, Worker demand $(\mathrm{Y})$ is transformed by $\log$-function, $\log (\mathrm{Y})$ as can converge to Normality distribution, Figure 2(b).

Since there are different types of nonlinear regression model, the relation pattern of $\log (\mathrm{Y})$ with other independent variables are observed. Next, the relation between $\log (\mathrm{Y})$ and other independent variables are shown in the scatter plot as Figure 3. The linear relation for all variables is not observed clearly. Several models either linear or nonlinear regression are explored

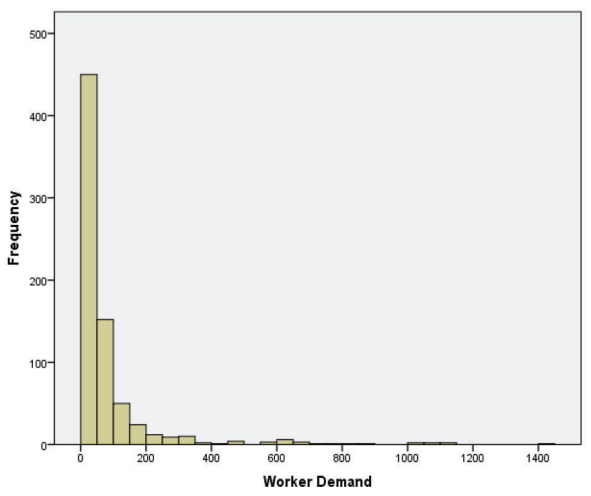

(a) Labor demand (Y)

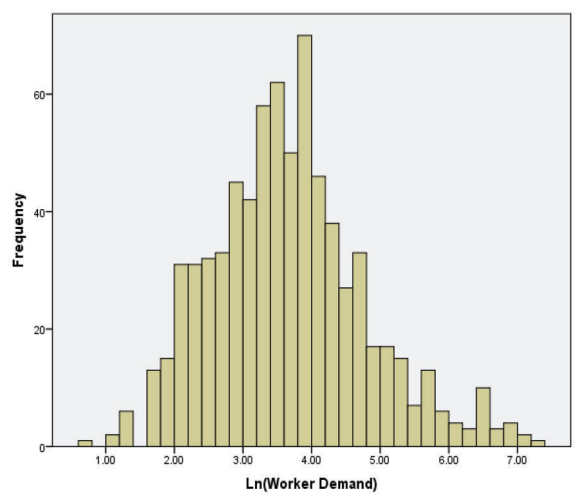

(b) $\log ($ Labor demand): $\log (\mathrm{Y})$

Figure 2 Histogram (Textile Industry). 

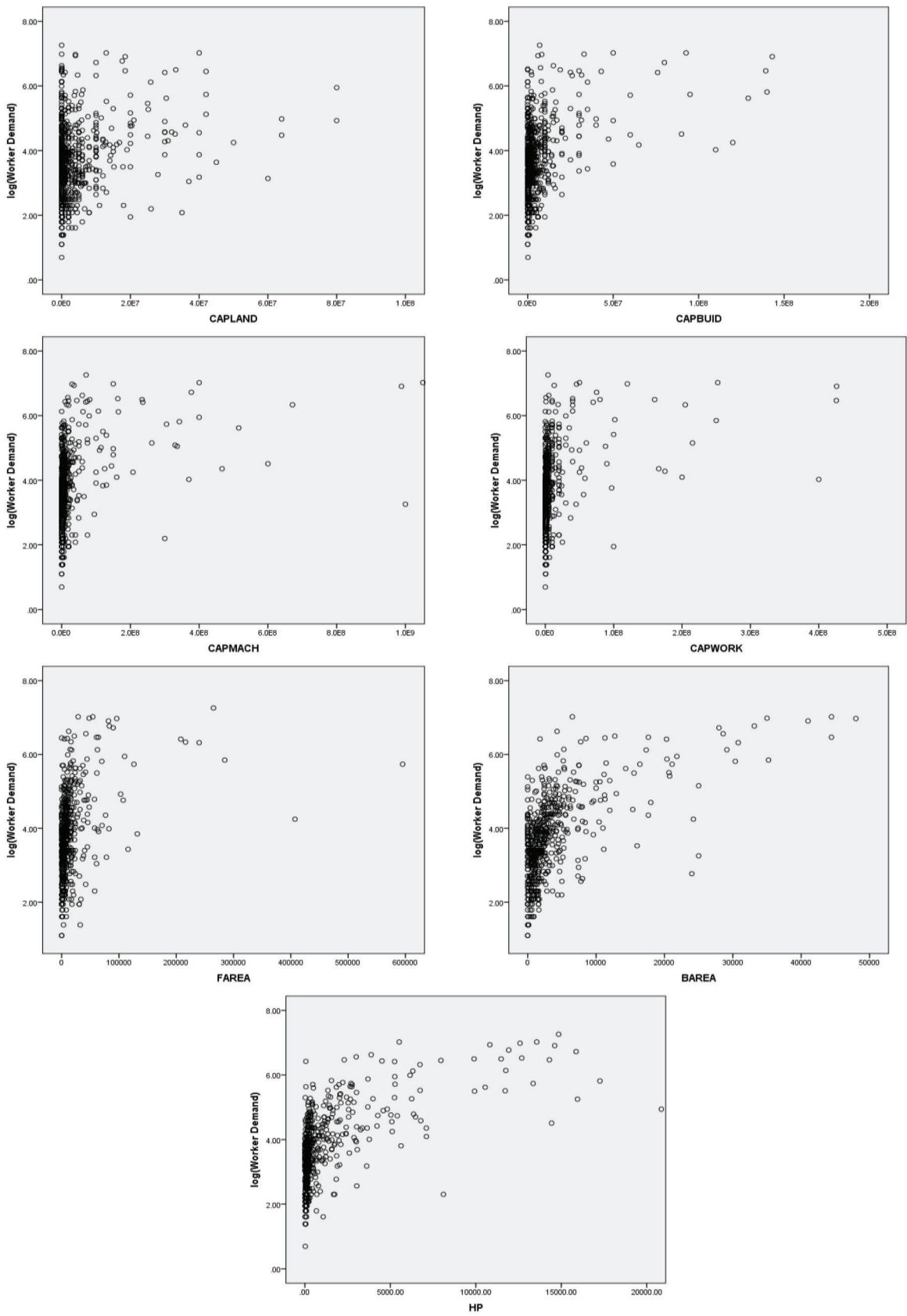

Figure 3 Scatter plot of $\log$ (Labor demand) and other dependent variables (Textile Industry). 
such as linear relation between $\log (\mathrm{Y})$ and independent variables by stepwise procedure, and different methods of independent variable transformation are explored. Particular models are rechecked for all assumptions and then are modified. The transforming model that satisfies all assumptions with high correlation coefficient is proposed as Equation (14).

By transforming $\mathrm{Y}$ and $\mathrm{X}_{7}$ with logarithm function, the power model (Equation (11)) is proposed as the transformation model for textile industry. Non-missing data of those two variables are obtained from 582 manufacturers in this model. The $\mathrm{F}$ test in the ANOVA (Table 5) shows $p$-values $<0.01$. Furthermore, Table 6 shows the regression coefficient of $\log \left(X_{7}\right)$ is not equal to 0 so the power model is shown in Equation (14).

$$
\log (\mathrm{Y})=1.466+0.391 \log \left(\mathrm{X}_{7}\right)
$$

The power model fulfils the regression assumptions since VIF is 1 (as there is only one independent variable), testing multivariate normality by P-P plot (Figure 4(b)) to show the relation in a straight diagonal line. In addition, scatter plot of residuals shows the residuals scatter around 0 randomly without pattern.

It is found that the adjusted coefficient determination $\left(\operatorname{adj} \mathrm{R}^{2}\right)$ of the linear model for textile manufacturer is 0.6271 with the $\mathrm{R}^{2}=0.6309$ which means that the linear regression explains $63.09 \%$ of the variance in the data. On the other hand, the adjusted $\mathrm{R}^{2}$ of power model for textile manufacturer is 0.4261 with the $\mathrm{R}^{2}=0.4271$ which means that the power regression model explains $42.71 \%$ of the variance in the Labour demand in textile industry. Generally, correlation coefficient $(\mathrm{R})$ indicates the strength of the association. $\mathrm{R}$ values

Table 5 Anova of the Power Model (Textile Industry)

\begin{tabular}{lcccccc}
\hline Source & SS & df & MS & F & $p$-value \\
\hline Reg. & 305.633 & 1 & 305.633 & 432.420 & $0.000^{*}$ \\
Res. & 409.942 & 580 & 0.707 & - & - \\
Total & 715.574 & 581 & - & - & - \\
\hline
\end{tabular}

*Significant at $p$-value $<0.01$ level.

Table 6 Coefficients of the Power Model (Textile Industry)

\begin{tabular}{lcccccc}
\hline Variable & $\hat{\beta}$ & $\mathrm{SE}$ & $\mathrm{t}$ & $p$-value & Tolerance & VIF \\
\hline (Constant) & 1.466 & 0.111 & 13.195 & $0.000^{*}$ & - & - \\
$\log ($ Horsepower $)\left(\log \left(\mathrm{X}_{7}\right)\right)$ & 0.391 & 0.019 & 20.795 & $0.000 *$ & 1.000 & 1.000 \\
\hline
\end{tabular}

*Significant at $p$-value $<0.01$ level. 


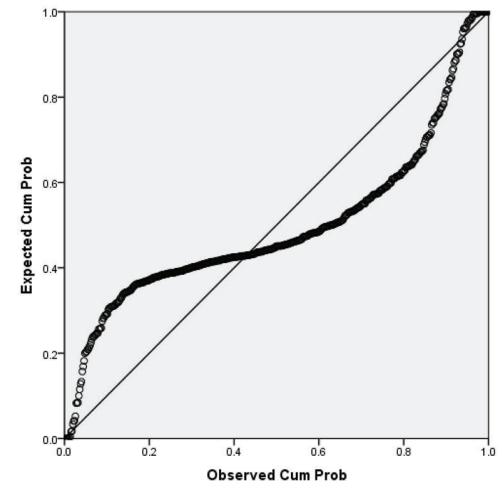

(a) Linear model

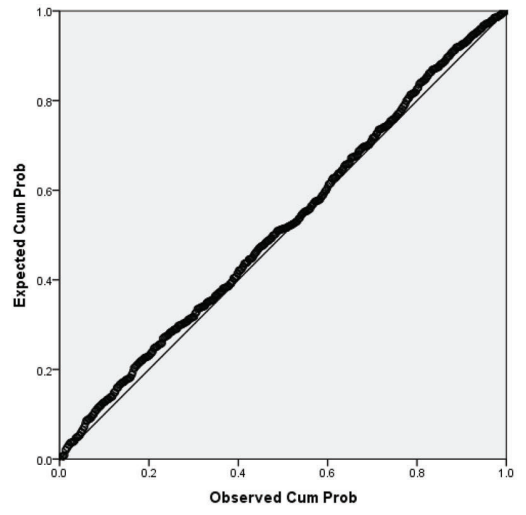

(b) Power model

Figure 4 Normal P-P Plot of regression standardized residual for model of textile industry.

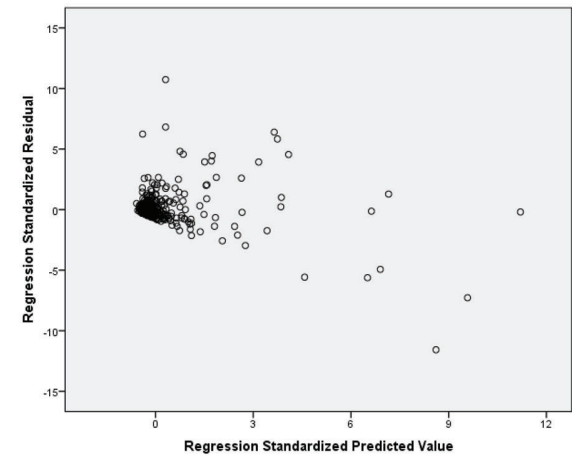

(a) Linear model

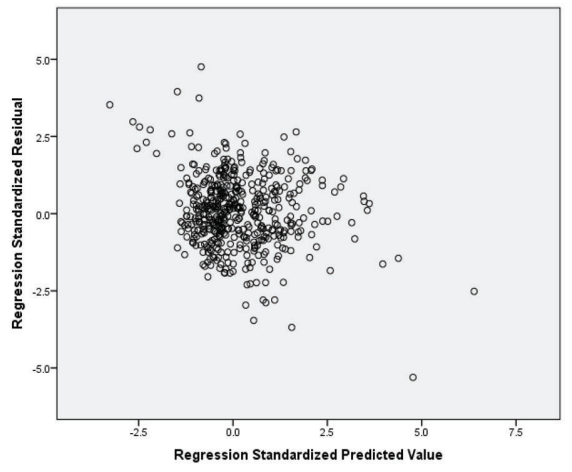

(b) Power model

Figure 5 Residual plot (Textile industry).

of the linear model is greater than the power model to show that the linear model associated with 5 independent variables is in higher association than the power model with 1 independent variable as illustrated in Table 7. Although, the correlation coefficient of the linear model is greater than power model,

Table 7 Model Summary for Textile Industry

\begin{tabular}{lccc}
\hline Model & $\mathrm{R}$ & $\mathrm{R}^{2}$ & $\mathrm{Adj} \mathrm{R}^{2}$ \\
\hline Linear model & 0.7943 & 0.6309 & 0.6271 \\
Power model & 0.6540 & 0.4271 & 0.4261 \\
\hline
\end{tabular}


the linear model was developed from data that do not follow the modelling assumptions so those problems results in a change in the signs as well as in the magnitudes of the partial regression coefficients from one sample to another sample. Consequently, it does not guarantee as a good labor demand forecasting model for textile industry.

\subsection{Garment Manufacturers}

There are 2,062 registered garment manufacturers and 656 completed data recorded so they are employed to the analysis. Table 8 shows the mean of workers in particular manufacturers is 244.08 persons. The machinery capital and working capital are as similar at 10,979,880 Baht and 10,385,550 Baht respectively. The mean factory area is $8,513.69 \mathrm{~m}^{2}$ and mean of building area is $2,411.27 \mathrm{~m}^{2}$. Finally, the mean operating capacity is $271.40 \mathrm{hp}$.

The $F$ test in the ANOVA (Table 9) shows that at least one of the defined independent variables is linearly related to the response variable ( $p$ values $<0.001)$. According to the results in Table 8, the result of multiple linear regression shows the variables that influence the labor demand in garment manufacturer are Building capital $\left(\mathrm{X}_{2}\right)$, Factory area $\left(\mathrm{X}_{5}\right)$, Type $\left(\mathrm{X}_{8}\right)$,

Table 8 Characteristics of the Garment Manufacturers

\begin{tabular}{lcccc}
\hline Variable & Mean & SE & Min & Max \\
\hline Labor demand $(\mathrm{Y})$ & 244.08 & 15.80 & 2 & 4,260 \\
Land capital $\left(\mathrm{X}_{1}\right)$ & $4,069.95$ & 840.05 & 0 & 515,000 \\
Building capital $\left(\mathrm{X}_{2}\right)$ & $7,958.79$ & 735.58 & 0 & 537,000 \\
Machinery capital $\left(\mathrm{X}_{3}\right)$ & $10,979.88$ & $1,341.52$ & 0 & 500,000 \\
Working capital $\left(\mathrm{X}_{4}\right)$ & $10,385.55$ & $1,343.04$ & 0 & 537,000 \\
Factory area $\left(\mathrm{X}_{5}\right)$ & $8,513.69$ & 834.80 & 0 & 265,008 \\
Building area $\left(\mathrm{X}_{6}\right)$ & $2,411.27$ & 298.74 & 0 & 147,200 \\
Horsepower $\left(\mathrm{X}_{7}\right)$ & 271.40 & 41.72 & 3 & 17,356 \\
\hline
\end{tabular}

Table 9 Anova of the Linear Model (Garment industry)

\begin{tabular}{lccccc}
\hline Source & SS & df & MS & F & $p$-value \\
\hline Reg. & $25,750,018.49$ & 6 & $4,291,669.75$ & 117.18 & $0.000 *$ \\
Res. & $24,245,523.98$ & 662 & $36,624.66$ & - & - \\
Total & $49,995,542.47$ & 668 & - & - & - \\
\hline
\end{tabular}

*Significant at $p$-value $<0.01$ level. 
Table 10 Coefficients of the Linear Model (Garment industry)

\begin{tabular}{lcccccc}
\hline Variable & $\hat{\beta}$ & $\mathrm{SE}$ & $\mathrm{t}$ & $p$-value & Tolerance & VIF \\
\hline (Constant) & 116.816 & 11.791 & 9.907 & $0.000^{*}$ & - & - \\
Building capital $\left(\mathrm{X}_{2}\right)$ & 0.006 & 0.001 & 8.206 & $0.000^{*}$ & 0.683 & 1.465 \\
Factory area $\left(\mathrm{X}_{5}\right)$ & 0.004 & 0.000 & 7.996 & $0.000^{*}$ & 0.743 & 1.345 \\
Type $\left(\mathrm{X}_{8}\right)$ & -109.748 & 15.448 & -7.104 & $0.000^{*}$ & 0.919 & 1.088 \\
Building area $\left(\mathrm{X}_{6}\right)$ & 0.008 & 0.001 & 6.781 & $0.000^{*}$ & 0.870 & 1.149 \\
Horsepower $\left(\mathrm{X}_{7}\right)$ & 0.040 & 0.013 & 2.962 & $0.003 *$ & 0.670 & 1.492 \\
Working capital $\left(\mathrm{X}_{4}\right)$ & 0.001 & $<0.000$ & 2.678 & $0.008^{*}$ & 0.681 & 1.468 \\
\hline
\end{tabular}

*Significant at $p$-value $<0.01$ level.

Building area $\left(\mathrm{X}_{6}\right)$, Horsepower $\left(\mathrm{X}_{7}\right)$, and Working capital $\left(\mathrm{X}_{4}\right)$ since $p$-value $<0.01$. As a result, regression equation to predict labor demand for a garment manufacturer is:

$$
\begin{aligned}
\mathrm{Y}= & 116.86+0.006 \mathrm{X}_{2}+0.004 \mathrm{X}_{5}-109.748 \mathrm{X}_{8}+0.008 \mathrm{X}_{6} \\
& +0.040 \mathrm{X}_{7}+0.001 \mathrm{X}_{4}
\end{aligned}
$$

Note: Type is dummy variable. Type $=1$ if the manufacturer is small size (up to 50 workers) and Type $=0$ if the manufacturer is large size (greater than 50 workers).

According to the model, the coefficients indicate that every 1,000 Baht of building capital can increase worker by 0.006 person, 1,000 Baht of working capital can increase worker by 0.001 persons. According to the area, each square meter of building area expect 0.008 worker to increase and total size of the factory with changes of a square meter would increase an average of 0.004 person. Every additional 1 horsepower needs 0.04 workers in production. Since Type is dummy variable, the small garment manufacturer needs 109.748 less than the large manufacturer as the base line.

The assumptions of regression analysis are investigated as below. Firstly, testing multivariate normality by P-P plot (Figure 8(a)) shows that data scatter out from a straight diagonal line so multivariate normality is not assumed. Secondly, by considering the Figure 9(a); scatter plot of residuals indicates linear relationships when they randomly spread around 0 without curvilinear pattern but without the same variance (same density both above and below the zero line). Therefore, assumption of a linear relationship is assumed but homoscedasticity is not assumed. Thirdly, the Durbin-Watson $=1.8193$, which is between the two critical values of 1.5 and 2.5. Therefore, we assume that there is no first order linear auto-correlation in the multiple linear regression 
data. Lastly, multicollinearity is considered in Table 12 and there is no VIF for individual variables which are greater than 10 or greater than 2.5 or with Tolerance less than 0.2 so that there is no multicollinearity for all defined independent variables in the defined model. Not all assumptions are passed, so we can improve the model with methods for variable transformation.

Firstly, we check whether the Labor demand (Y) that is marginally normally distributed. The histogram (Figure 6(a)) shows the Labor demand $(\mathrm{Y})$ is non-normal distribution with right skew. Therefore, Labor demand $(\mathrm{Y})$ is transformed by $\log$-function, $\log (\mathrm{Y})$ as it converges to Normality distribution in Figure 6(b). Next, data preparation for regression analysis is employed and it was found that six cases are omitted from this analysis since they are outliers since the Cook's distance of those cases are greater than 1 . Therefore, we employ 650 cases for regression analysis.

The relation pattern of $\log (\mathrm{Y})$ with other independent variables are observed by considering the relation between $\log (\mathrm{Y})$ and other independent variables are shown in the scatter plot as Figure 7. The linear relation between $\log (\mathrm{Y})$ with other dependent variables are explored with stepwise approach and with single independent variable transformation. Those possible models are compared the power model with Horsepower selected, as shown in the equation below.

The relationship between $\log (\mathrm{Y})$ and eight defined variables are analysed and the proposed model is formed by transforming both Labor demand and Horsepower with logarithm function called a power model. The F test in the ANOVA (Table 11) shows that at least one of the defined independent variables is linearly related to the response variable ( $p$-values $<0.01$ ).

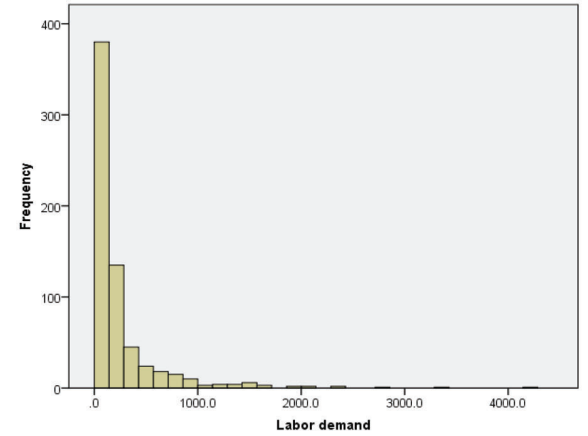

(a) Labor demand (Y)

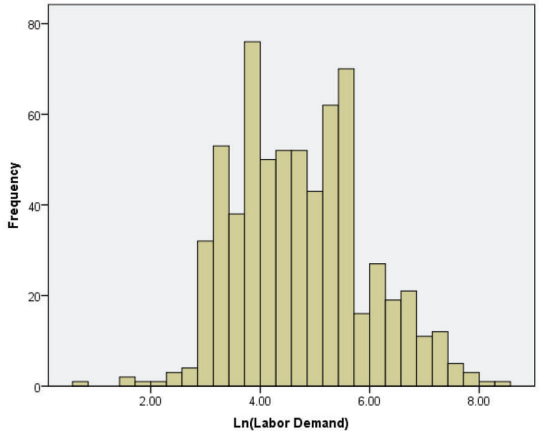

(b) $\log ($ Labor demand): $\log (\mathrm{Y})$

Figure 6 Histogram (Garment Industry). 

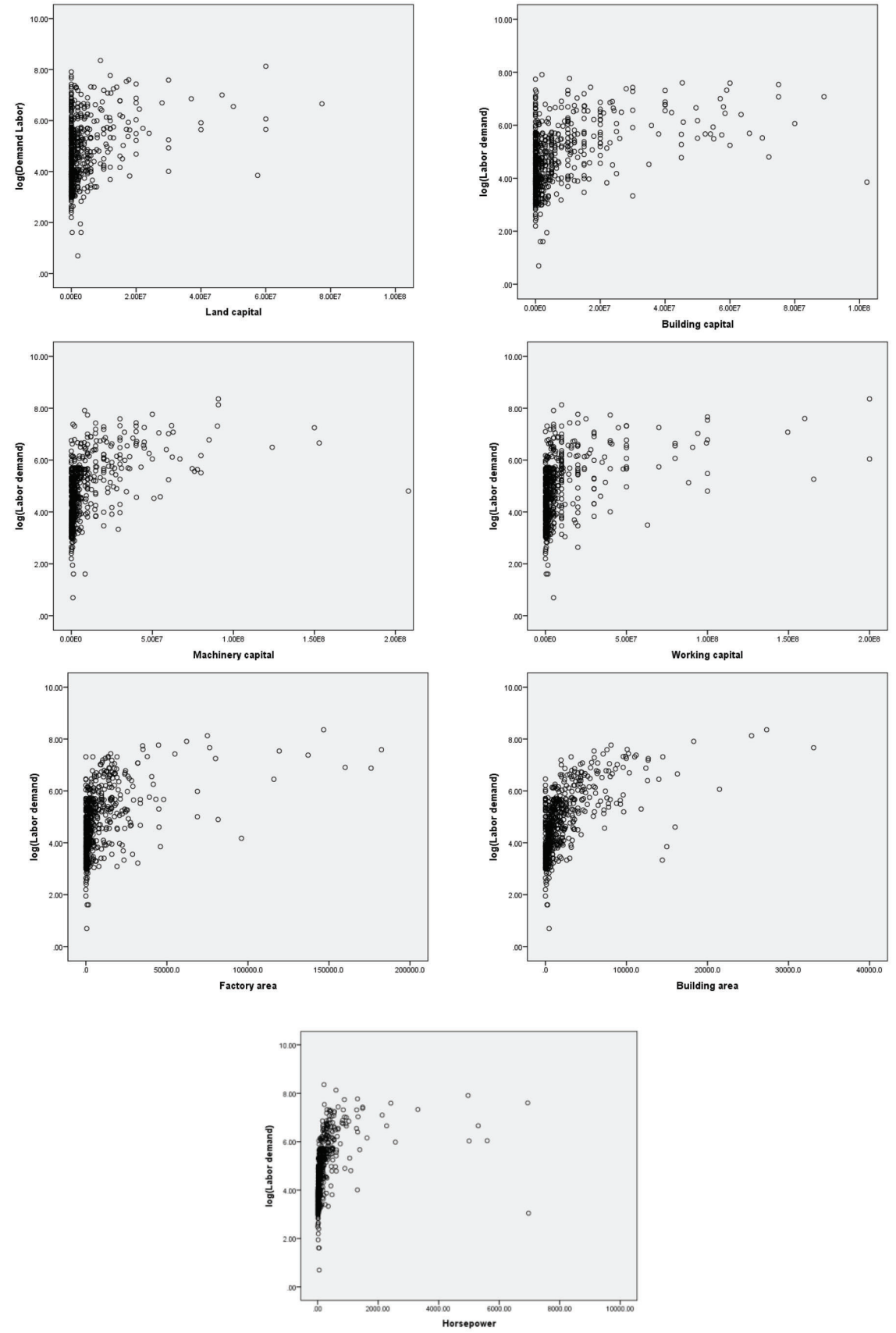

Figure 7 Scatter plot (Garment Industry). 
Table 11 Anova of the Power Model (Garment industry)

\begin{tabular}{lccccc}
\hline Source & SS & df & MS & F & $p$-value \\
\hline Reg. & 1202.837 & 1 & 1202.837 & 3196.772 & $0.000^{*}$ \\
Res. & 610.680 & 1623 & 0.376 & - & - \\
Total & 1813.517 & 1624 & - & - & - \\
\hline
\end{tabular}

*Significant at $p$-value $<0.01$ level.

Table 12 Coefficients of the Power Model (Garment industry)

\begin{tabular}{lcccccc}
\hline Variable & $\hat{\beta}$ & $\mathrm{SE}$ & $\mathrm{t}$ & $p$-value & Tolerance & VIF \\
\hline (Constant) & 1.968 & .044 & 45.016 & $0.000^{*}$ & & \\
$\log ($ Horsepower $)\left(\log \left(\mathrm{X}_{7}\right)\right)$ & 0.636 & .011 & 56.540 & $0.000^{*}$ & 1.000 & 1.000 \\
\hline
\end{tabular}

*Significant at $p$-value $<0.01$ level.

According to the results in Table 12, the variables that influence the labor demand with logarithm transformation in garment manufacturer are logarithm of horsepower, since $p$-value $<0.01$. The regression equation shows relation equation to predict the labor demand that transform to $\log (\mathrm{Y})$ from the only one variable for a garment manufacturer in Equation (16).

$$
\log (\mathrm{Y})=1.968+0.636 \log \left(\mathrm{X}_{7}\right)
$$

The appropriate of proposed regression model is confirmed by the results of assumption verification. Firstly, Figure 8(b) shows the distribution of residual of the model is normality as the expected cumulative probability of $\log (\mathrm{y})$ distributes along the straight diagonal line so the normality distribution is assumed. Secondly, residual plot in Figure 9(b) indicates linear relationships which assumed as residuals randomly spread around 0 without curvilinear pattern. Thirdly, the density of both above and below the zero line is equivalent. Therefore, assumption of homoscedasticity is assumed. Fourthly, the DurbinWatson $=1.6649$, therefore there is no first order linear auto-correlation in the multiple linear regression data. Lastly, multicollinearity test can be accepted since there is only one independent variable in this model.

It is found that the adjusted coefficient determination $\left(\operatorname{adj} R^{2}\right)$ of the linear model for garment manufacturer is 0.5107 with the $\mathrm{R}^{2}=0.5150$, which means that the linear regression explains $51.50 \%$ of the variance in the data. On the other hand, adj $\mathrm{R}^{2}$ of the power model is 0.6631 with the $\mathrm{R}^{2}=0.6633$, which means that the power model explains $66.33 \%$ of the labor demand in textile industry. It is also found that adj $\mathrm{R}^{2}$ of the power model with one independent variable is higher than adj $\mathrm{R}^{2}$ of the linear model with six independent variables. 


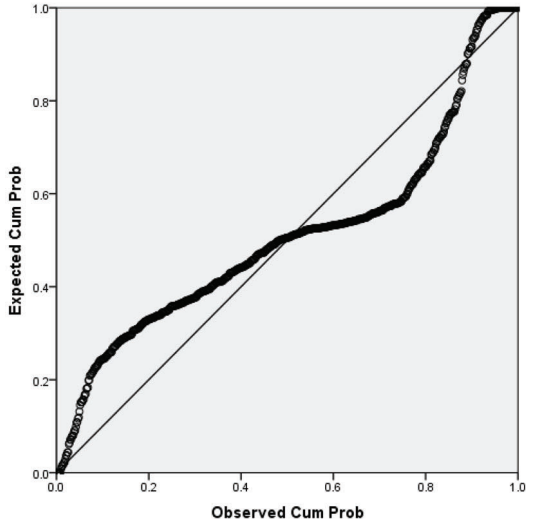

(a) Linear model

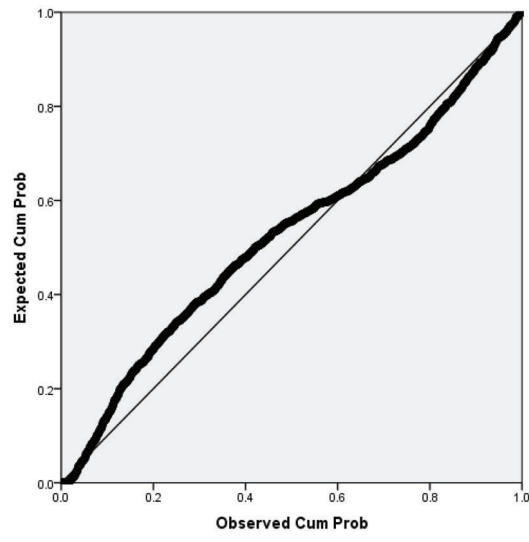

(b) Power model

Figure 8 Normal P-P Plot of regression standardized residual for model of garment industry.

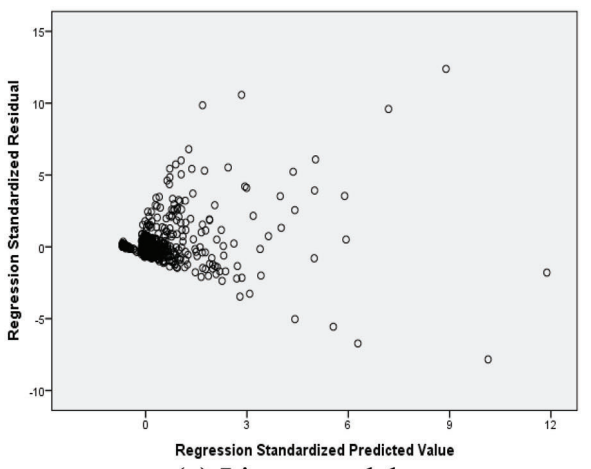

(a) Linear model

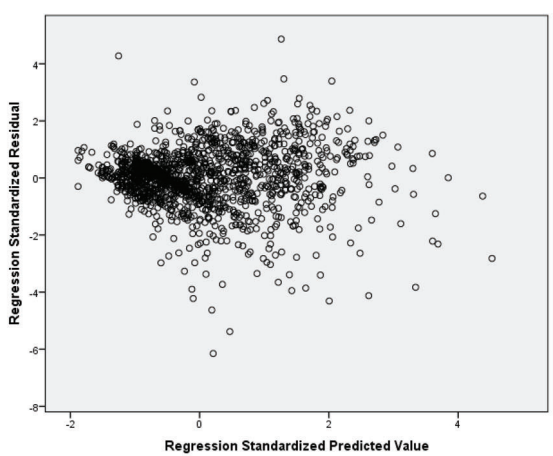

(b) Power model

Figure 9 Residual plot (Garment industry).

Furthermore, correlation coefficient $(\mathrm{R})$ of the power model is higher than $\mathrm{R}$ value of the linear model which means there is higher linear association between the dependent variable and the independent variable(s). Furthermore, $\mathrm{R}$ of those two models is between $0.7-0.9$ which can show high association as illustrated in Table 13.

Table 13 Model Summary for Garment Industry

\begin{tabular}{lccc}
\hline Model & $\mathrm{R}$ & $\mathrm{R}^{2}$ & $\mathrm{Adj} \mathrm{R}^{2}$ \\
\hline Linear model & 0.7177 & 0.5150 & 0.5107 \\
Power model & 0.8140 & 0.6633 & 0.6631 \\
\hline
\end{tabular}




\section{K. Leerojanaprapa and K. Bhundarak}

\section{Conclusion and Further Studies}

There are two objectives for this article. The first objective is to define the correlation between particular resource variables with the labour demand which can be explained by the linear model for both industries. The second objective is to define the suitable forecasting model to predict labour demands by proposing the model which satisfied all modelling assumptions.

According to the multiple linear models for textile and garment industries (Equation (13) and Equation (15)), it is found that textile and garment manufacturers are different in nature although they are in the same supply chain. The textile sector relies on technology and machinery so the textile fiber manufacturers invested a lot of money in machinery (high mean value of Machinery capital). As a result, the new technologies invested can reduce number of workers in their process but they may need high skilled workers to be able to implement the technology. On the hand, the garment sector remains one of the most labor intensive industries and they are different in size of manufacturers. They need a lot of workers in manufacturing process e.g. sawing or cutting so mean of number of workers is higher than textile fiber manufacturer.

However; those linear models could not meet the associated assumptions by linear relationship and homoscedasticity. This study also improves the liner model by using transformations to achieve all regression assumptions in order to fulfil the second objectives. The power model constructs the relationship between $\log$ (Labour demand) and $\log$ (Horsepower) which can reduce the complexity of using multivariate predictors in order to ensure that the model can be a suitable forecasting model under the defined modelling assumptions. The power model proposed for garment industry (Equation (14)) can show the better forecasting model than the power model for textile industry (Equation (16)) as shown by the higher number of correlation coefficient (R) and a multiple correlation coefficient $\left(\mathrm{R}^{2}\right)$.

This article proposes the basic forecasting model for cross-sectional data particularly textile and garment companies in Thailand which can be used as the initial guideline for workforce planning. For further improvements, more relevant variables to the labor demand should be defined since the limited numbers of variables are available in this record as the secondary data. In addition, time series data should be brought to the further studies. 


\section{References}

[1] Bureau of Labor Statistics. (2015). Projections of the Labor Force, 201424. Available at: http://www.bls.gov/careeroutlook/2015/article/projectio ns-laborforce.htm [Accessed: 16-Feb-2016].

[2] Samuelson, P. A. and Nordhaus, W. D. (2005). Macroeconomics, 18th Edn. Boston, MA: McGraw-Hill/Irwin. Available at: http://trove.nla.gov.au/version/13058406

[3] The Office of Industrial Economics. (2016). Industrial Economic Conditions in 2016 and Outlook for 2017.

[4] Osborne, J. W., Christensen, W. R., and Gunter, J. (2001). Educational Psychology from a Statistician's Perspective: A Review of the Power and Goodness of Educational Psychology Research. In National Meeting of the American Education Research Association (AERA), Seattle, WA.

[5] Region Government of the Hong Kong Administrative. (2012). Report on Manpower Projection to 2018.

[6] Nadvi, K., Thoburn, J. T., Thang, B. T., Ha, N. T. T., Hoa, N. T., Le, D. H., and Armas, E. B. D. (2004). Vietnam in the global garment and textile value chain: impacts on firms and workers. J. Int. Dev., 16, 111-123.

[7] Taplin, Ian M., Jonathan Winterton, and Ruth Winterton. (2003) "Understanding labour turnover in a labour intensive industry: evidence from the British clothing industry." J. Manage. Stud. 40, 1021-1046.

[8] Dong, J., Ren, C., Ren, S., Shao, B., Wang, Q., Wang, W., and Ding, H. (2008). iRDM: A solution for workforce supply chain management in an outsourcing environment. In Service Operations and Logistics, and Informatics, IEEE/SOLI 2008. IEEE International Conference, Vol. 2, 2496-2501.

[9] Scheffler, R. M., Liu, J. X., Kinfu, Y., and Dal Poz, M. R. (2008). Forecasting the global shortage of physicians: an economic-and needs-based approach. Bull. World Health Organ. 86, 516-523.

[10] Liu, J., Love, P. E., Sing, M. C., Carey, B., and Matthews, J. (2015). Modeling Australia's construction workforce demand: Empirical study with a global economic perspective. J. Constr. Eng. Manag. 141, p. 5014019. 
[11] Wong, J. M., Chan, A. P., and Chiang, Y. H. (2011). Construction manpower demand forecasting: A comparative study of univariate time series, multiple regression and econometric modelling techniques. Eng. Constr. Archit. Manag. 18, 7-29.

[12] Wong, J. M., Chan, A. P., and Chiang, Y. H. (2005). Time series forecasts of the construction labour market in Hong Kong: the Box-Jenkins approach. Constr. Manage. Econ. 23, 979-991.

[13] U. S. B. of L. Statistics. (1929). Handbook of labor statistics, U.S. G.P.O.

\section{Biographies}

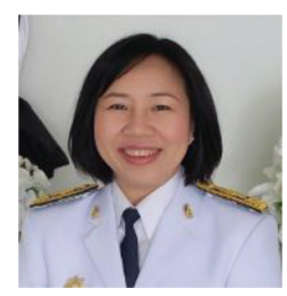

Kanogkan Leerojanaprapa went to the Thammasat University, where she studied Applied Statistics and obtained her degree in 1999. She continued to study Master degree in Statistics in Chulalongkorn University and obtained her degree in 2002. She worked for four years for King Mongkut's Institute of Technology Ladkrabang (KMITL). She holds a PhD in Management science since 2014 from University of Strathclyde, UK. After her graduation, she returned to KMITL where she is now a lecturer in Statistics department. Her research focus in the area of risk analysis, Bayesian network, and applications of statistical models. She has published articles in various peer reviewed international journals and conferences. 


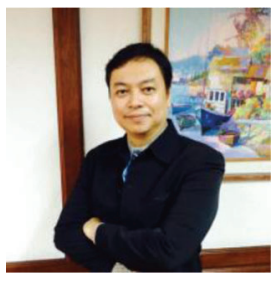

Komn Bhundarak obtained a B.BA. in Industrial Management from Faculty of Accountancy and Commerce, Thammasat University, in 1985. He worked for $3 \mathrm{M}$ Thailand more than 10 years while pursuited MBA from Thammasat University in 1989 and Master of Science in Infornation Technology from Kasetsart University in 2001. Then he became a lecturer in 2009 and earned his Doctoral in Business with Management since 2014 from University of Plymouth, UK. After his graduation, he joined Thammasat Business School, Thammasat University, where he is now a Department Head, Operations Management Department. His research focus in the area of supply chain management and business analytics. 
